\title{
Simultaneous Estimation of Dosulepin and Methylcobalamin in Bulk and Pharmaceutical Formulation by Reverse Phase High Performance Liquid Chromatography (RP-HPLC)
}

\author{
Usharani gundala*1 ${ }^{1}$, Chandrashekar Bonagiri ${ }^{2}$, Devanna nayakanti ${ }^{3}$ \\ ${ }^{I}$ Research Scholar, JNTUA, Anantapur, A.P, INDIA. \\ ${ }^{2}$ Professor, MLR Institute of Pharmacy, Hyderabad, A.P, INDIA. \\ ${ }^{3}$ Director of OTRI, JNTUA, Anantapur, A.P, INDIA.
}

\begin{abstract}
A simple, specific and cost effective RP-HPLC method was developed for simultaneous estimation of Dosulepin and Methylcobalamin in bulk. In addition the developed method was applied to the suitable combined tablet dosage form ie., Prothiaden. As there is no UV or HPLC method for the simultaneous estimation of Dosulepin and Methylcobalamin, a need was felt to develop the method for the analysis of both drugs simultaneously. Chromatography was carried on Zorbax C8 column $(150 x 4.5,5)$ with mobile phase comprising of Ortho Phosphoric Acid buffer and Methanol in the ratio of 50:50 v/v. The flow rate was adjusted to 0.8 $\mathrm{ml} / \mathrm{min}$ with PDA detection at $219.8 \mathrm{~nm}$. The retention times of Dosulepin and Methylcobalamin were found to be $3.8 \mathrm{~min}, 1.9 \mathrm{~min}$ respectively and other replicate standard system suitability parameters are within the limit and uniform. The different analytical parameters such as accuracy, precision, linearity, robustness, limit of detection (LOD), limit of quantification ( $L O Q$ ) were determined according to the International Conference on Harmonization (ICH) Q2B guidelines. The detector response was linear in the range of 0.9-2.7 mg/ml., 0.018$0.054 \mathrm{mg} / \mathrm{ml}$ for Dosulepin and Methylcobalamin respectively. The proposed method was successfully applied for the reliable quantification of active pharmaceuticals present in the commercial formulations.
\end{abstract}

Keywords: Dosulepin, Methylcobalamin, HPLC, Methanol, Ortho Phosphoric Acid.

\section{Introduction}

Dosulepin (Fig. 1) is chemically 3-(6H-dibenzo[b,e]thiepin-11-ylidene)propyldimethylamine hydrochloride[1,2]. DOS is a Tricyclic antidepressant (TCA), which inhibit the active reuptake of biogenic amines NA and 5-HT in to their respective neurons [3]. Methylcobalamin (Fig. 2) is a dark red crystalline powder and it has been referred for neurological illness, diabetic neuropathy, hearing loss and Alzheimer's disease. Methylcobalamin is chemically $\operatorname{Co} \alpha-[\alpha-$ (5, 6-dimethylbenz-1H-imidazolyl)]- Coßmethylcobamide [1-5]. Literature survey revealed there is no published chromatographic method for this combination of drug.<smiles>CCCCCN(C)CCC=C1c2ccccc2CSc2ccccc21</smiles>

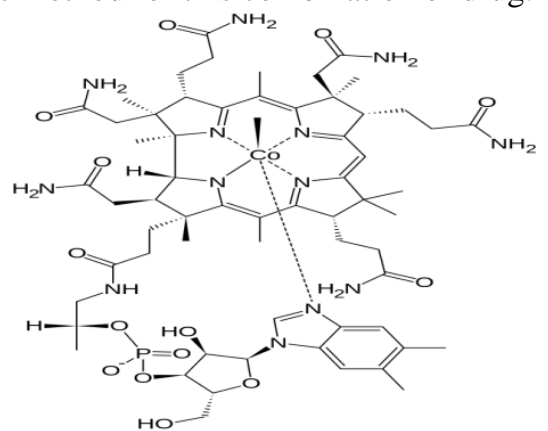

Fig.2

The present paper describes a simple, accurate and precise method for reverse phase liquid chromatographic estimation of DOS and MCA in combined tablet dosage form. The proposed method is optimized and validated as per the International Conference on Harmonization (ICH) guidelines [6,7]. In the present work, a successful attempt has been made to estimate both these drugs simultaneously by RP-HPLC method $[8,9,10]$. 


\subsection{Materials:}

\section{Materials And Methods:}

\subsubsection{Chemicals and Reagents:}

Working standards of pharmaceutical grade Dosulepin and Methylcobalamin were obtained as generous gifts from Dr.Reddy's laboratories (Hyderabad, AP, India) used as such without further purification. The pharmaceutical dosage form used in the study was Prothiaden.

Methanol (HPLC grade), Orthophosphoric acid (AR grade) purchased from Merck specialities Pvt.ltd (Mumbai, India) and double distilled water used for analysis.

\subsubsection{Instrumentation and chromatographic condition:}

Chromatography was carried out on Zorbax C8 column $(150 \times 4.5,5)$ with mobile phase comprising of orthophosphoric acid buffer and Methanol in the ratio of 50:50 v/v. The flow rate was adjusted to $0.8 \mathrm{ml} / \mathrm{min}$ with PDA detection at $219.8 \mathrm{~nm}$.

\subsubsection{Preparation of standard solution:}

Standard stock solutions of pure drugs were prepared separately by dissolving $18 \mathrm{mg}$ of Dosulepin in $10 \mathrm{ml}$ water and $3.6 \mathrm{mg}$ of Methylcobalamin in $100 \mathrm{ml}$ water to get concentrations $1.8 \mathrm{mg} / \mathrm{ml}$ and $0.036 \mathrm{mg} / \mathrm{ml}$ respectively.

\subsubsection{Preparation of sample solution:}

20 tablets were weighed accurately, powdered and equivalent weight was calculated. The equivalent weight of twelve tablets were taken and dissolved in $30 \mathrm{ml}$ of water, sonicated for 25 minutes, made up to $50 \mathrm{ml}$ volume and filtered to get the concentration $1.8 \mathrm{mg} / \mathrm{ml}$ of Dosulepin and $0.036 \mathrm{mg} / \mathrm{ml}$ of Methylcobalamin.

\subsection{Validation:}

The developed method was validated with different analytical parameters such as accuracy, precision, linearity, limit of detection, limit of quantification and robustness according to the international conference on harmonization (ICH) Q2B guidelines.

\subsubsection{Precision:}

Precision of these methods was checked by analyzing the samples at three different time intervals of the same day (intraday precision (table-2)) as well as on different days (interday precision). Robustness for HPLC method was performed by deliberately changing the chromatographic conditions. The flow rate of the mobile phase was changed from $0.8 \mathrm{~mL} / \mathrm{min}$ to $0.6 \mathrm{~mL} / \mathrm{min}$ and $1.0 \mathrm{~mL} / \mathrm{min}$ while ratio of the mobile phase was changed by $\pm 1 \%$.

Table-2: Validation parameters:

\begin{tabular}{|c|c|c|}
\hline Validation Parameter & Dosulepin & Methylcobalamin \\
\hline ystem precision & $0.1 \%$ & $0.1 \%$ \\
\hline Tailing factor & 1.1 & 1.4 \\
\hline Theoretical plate count & 4670 & 3130 \\
\hline Linearity & $900-2700 \mu \mathrm{g} / \mathrm{ml}, 54 \mu \mathrm{g} / \mathrm{ml}$ \\
\hline Regression equation & $\mathrm{y}=21048 \mathrm{x}+11130$ & $\mathrm{y}=22600 \mathrm{x}+1828$ \\
\hline Regression coefficient & 1 & $1.69 \mu \mathrm{g} / \mathrm{ml}$ \\
\hline Detection limit $(\mu \mathrm{g} / \mathrm{mL})$ & $5.86 \mu \mathrm{g} / \mathrm{ml}$ & $5.63 \mu \mathrm{g} / \mathrm{ml}$ \\
\hline Quantitation limit $(\mu \mathrm{g} / \mathrm{mL})$ & $19.55 \mu \mathrm{g} / \mathrm{ml}$ & $97 \%$ \\
\hline Accuracy $\%$ recovery) & $101 \%$ & $100 \%$ \\
\hline \multicolumn{2}{|c|}{ Precision } & 0.57 \\
\hline Assay value & Intra-day Precision & $99 \%$ \\
\hline \%RSD & $100 \%$ & 0.2 \\
\hline Assay value & 0.97 & \\
\hline \%RD & Inter-day Precision & \\
\hline
\end{tabular}

\subsubsection{Recovery studies:}

To check the accuracy of the developed methods and to study the interference of formulation additives, analytical recovery experiments were carried out by standard addition method at 50,100, 150\% levels (table 2 and 3). From the total amount of drug found percentage recovery was calculated. 
Table-2 : Recovery studies of Dosulepin

\begin{tabular}{|c|c|c|c|c|c|}
\hline \% Concentration & Area & Amount Added $(\boldsymbol{\mu g})$ & Amount Found $(\boldsymbol{\mu g})$ & \% Recovery & Mean Recovery \\
\hline $50 \%$ & 10588540 & 900 & 904 & $101 \%$ & \\
\hline $100 \%$ & 21044263 & 1800 & 1815.5 & $101 \%$ & $101 \%$ \\
\hline $150 \%$ & 31548507 & 2700 & 2695.4 & $100 \%$ & \\
\hline
\end{tabular}

Table-3: Recovery studies of Methylcobalamin

\begin{tabular}{|c|c|c|c|c|c|}
\hline \% Concentration & Area & Amount Added( $\boldsymbol{\mu g})$ & Amount Found( $\boldsymbol{\mu g})$ & \% Recovery & Mean Recovery \\
\hline $50 \%$ & 1124612 & 18 & 17.98 & $100 \%$ & \\
\hline $100 \%$ & 2255945 & 36 & 34.98 & $97 \%$ & $100 \%$ \\
\hline $150 \%$ & 3372120 & 54 & 54.22 & $100 \%$ & \\
\hline
\end{tabular}

\subsubsection{Linearity:}

\section{LOD and LOQ:}

Limit of Detection (LOD) and Limit of quantification (LOQ) were calculated by using the values of slopes and intercepts of the calibration curves for both the drugs. LOD and LOQ values for Dosulepin were found to be $5.86 \mu \mathrm{g} / \mathrm{ml}$ and $19.55 \mu \mathrm{g} / \mathrm{ml}$ and for Paracetamol $1.69 \mu \mathrm{g} / \mathrm{ml}$ and $5.63 \mu \mathrm{g} / \mathrm{ml}$ respectively.

\subsubsection{Robustness:}

Method robustness was determined by the small changes in chromatographic conditions like as $0.2 \mathrm{ml}$ flow rate and $\pm 5^{\circ} \mathrm{c}$ temperature and inject the sample observe the result there were no marked changes compare to other analysis. Results of the Robustness were shown in table-3.

Table-4: Robustness study

\begin{tabular}{|c|c|c|}
\hline Parameters & Changes & Retention Time \\
\hline \multicolumn{3}{|c|}{ Dosulepin } \\
\hline \multirow[t]{2}{*}{ Flow rate $(\mathrm{ml} / \mathrm{min})$} & 0.6 & 4.36 \\
\hline & 1.0 & 3.42 \\
\hline \multirow[t]{2}{*}{ Temperature } & $45^{\circ} \mathrm{C}$ & 4.87 \\
\hline & $55^{\circ} \mathrm{C}$ & 5.31 \\
\hline \multicolumn{3}{|c|}{ Methylcobalamin } \\
\hline \multirow[t]{2}{*}{ Flow rate $(\mathrm{ml} / \mathrm{min})$} & 0.6 & 2.20 \\
\hline & 1.0 & 1.72 \\
\hline \multirow[t]{2}{*}{ Temperature } & $45^{\circ} \mathrm{C}$ & 2.35 \\
\hline & $55^{\circ} \mathrm{C}$ & 2.65 \\
\hline
\end{tabular}

\section{Results And Discussion:}

Retention times of Dosulepin and Methylcobalamin were found to be 3.8 and 1.9 respectively (as shown in Fig. 3). The detector response was linear in the range of 900-2700 $\mu \mathrm{g} / \mathrm{ml}, 18-54 \mu \mathrm{g} / \mathrm{ml}$ for Dosulepin and Methylcobalamin respectively. In the linearity study the regression equation and coefficient of correlation for Dosulepin and Methylcobalamin were found to be $\left(y=21048 x+11130, R^{2}=1\right),(y=22600 x+1828$ $\mathrm{R}^{2}=1$ ) respectively. Linearity of Dosulepin and Methylcobalamin were shown in Fig. 4 and Fig. 5 respectively. Commercial formulations containing Dosulepin and Methylcobalamin were analyzed by the proposed method. A typical chromatogram of marketed formulation is shown in fig. no.3. Six replicate analysis of formulation were carried out and the mean assay values were found close to $100 \%$. The tailing factors were $<2.0$ for both the peaks. The elution order was Dosulepin $(\mathrm{RT}=3.8 \mathrm{~min})$ and Methylcobalamin $(\mathrm{RT}=1.9 \mathrm{~min})$, at a flow rate of $0.8 \mathrm{~mL} / \mathrm{min}$. The chromatogram was recorded at $219.8 \mathrm{~nm}$. System suitability was established by injecting standard solution and results are shown in table no.1.The accuracy of the proposed method was determined by recovery studies. It was confirmed from results that the method is highly accurate (table no.2 and 3 ). Precision (table no.1) was calculated as interday and intraday variations for both the drugs. Percent relative standard deviations for intraday and interday precision for Dosulepin were $0.97 \%$ and $0.1 \%$ and that for Methylcobalamin were $0.57 \%$ and $0.2 \%$ respectively which are well within the acceptable limit of $2 \%$. For robustness studies in all deliberately varied conditions, the RSD of contents of Dosulepin and Methylcobalamin were found to be well within the acceptable limit of $2 \%$. 


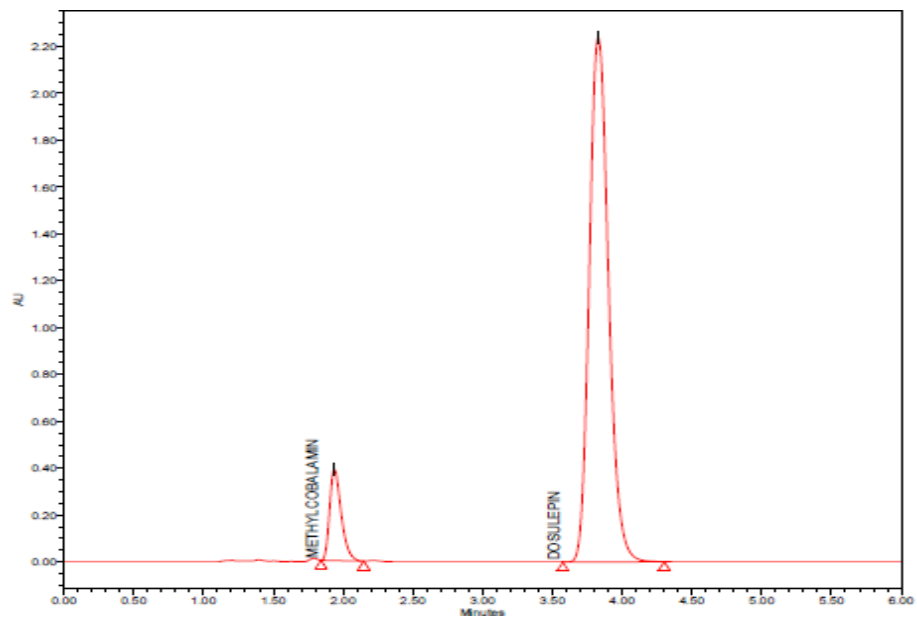

Fig. 3

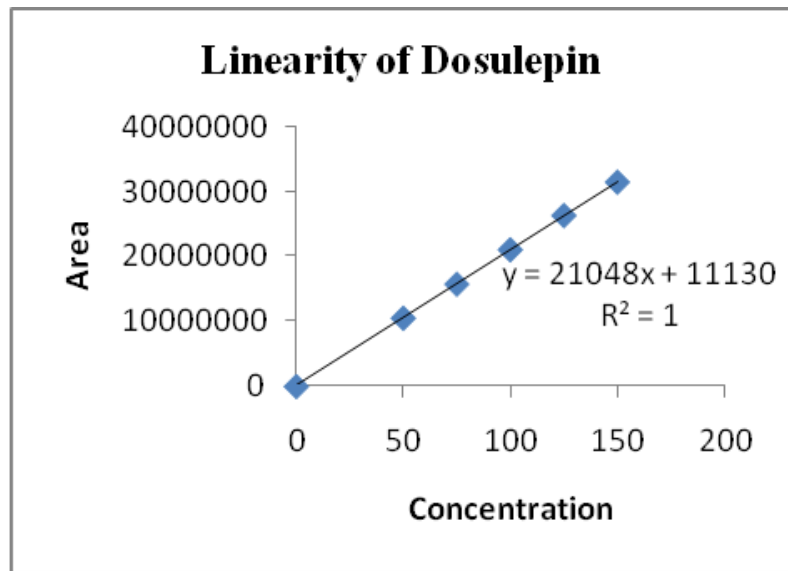

Fig. 4

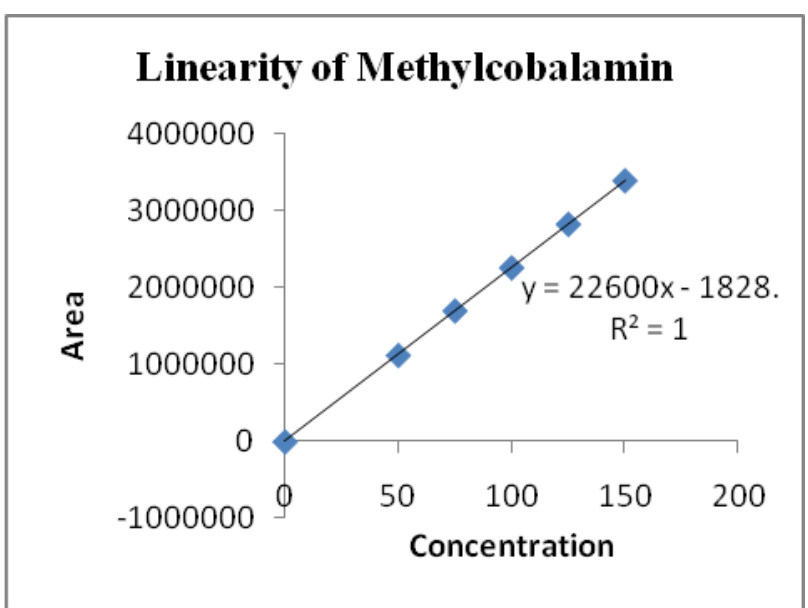

Fig. 5

IV. Conclusion:

The new HPLC method developed and validated for simultaneous estimation of Dosulepin and Methylcobalamin pharmaceutical dosage forms and assured the satisfactory precision and accuracy and also determining lower concentration of each drug in its solid combined dosage form by RP-HPLC method. The method was found to be simple, accurate, precise, economical and rapid and they can be applied for routine analysis in laboratories and is suitable for the quality control of the raw materials, formulations, dissolution studies and can be employed for bioequivalence studies for the same formulation. 


\section{Acknowledgement:}

Authors thank full to Rainbow Pharma training lab, Kukatpally, Hyderabad and JNTUniversity, Anantapur, for providing instruments and analytical support.

\section{References}

[1]. Indian Pharmacopoeia; Indian Pharmacopoeia commission, Ghaziabad, volume- II, p. 1250; 2010

[2]. British Pharmacopoeia; British Pharmacopoeia Commission Office, London, volume- I, p. 758- 759; 2011.

[3]. Martindale- The Extra Pharmacopoeia; 31st Edn; The Royal Pharmaceutical Society, London, p. $310 ; 1996$.

[4]. Beckette AH and Stenlake JB. Practical Pharmaceutical Chemistry, 4th ed. Vol II. CBS Publishers, New Delhi. 1997; 275.

[5]. British Pharmacopeia. British Pharmacopeal Commission. Vol III, London. 2004; 2334

[6]. Bently and Driver's. Textbook of Pharmaceutical Chemistry. 8th ed. Oxford university press. London. $2003 ; 9$ \& 876

[7]. Sethi PD. Quantitative Analysis of Pharmaceutical formulations. 1st ed. CBS Publishers \& Distributors. New Delhi. 1985; 212 \& 879

[8]. Takeuru Higuchi. Pharmaceutical Analysis. 1st ed. CBS Publishers \& Distributors. New Delhi. 2004; 671-680. 